\title{
An experimental investigation of the explosion characteristics of dimethyl ether-air mixtures
}

\author{
Bo Zhang ${ }^{1,2+}$, Hoi Dick $\mathrm{Ng}^{3}$ \\ ${ }^{1}$ East China University of Science and Technology \\ State Environmental Protection Key Laboratory of Environmental Risk Assessment and Control \\ on Chemical Process, Shanghai, 200237, China \\ ${ }^{2}$ Beijing Institute of Technology \\ State Key Laboratory of Explosion Science and Technology, Beijing, 100081, China \\ ${ }^{3}$ Concordia University \\ Department of Mechanical and Industrial Engineering \\ Montréal, QC, H3G 1M8, Canada \\ ${ }^{\dagger}$ Corresponding Author \\ E-mail: bzhang@ecust.edu.cn \\ Tel.: (86) 21-64253132 \\ Fax: (86) 21-64253404
}




\title{
An experimental investigation of the explosion characteristics of dimethyl ether-air mixtures
}

\author{
Abstract
}

In this work, experiments are performed to study the explosion characteristics of dimethyl ether (DME) -air mixtures using a standard 20-L spherical explosion test apparatus. The experimental data reported in this paper includes: the maximum explosion pressure $\left(p_{\max }\right)$, flammability limits, maximum rate of pressure rise $(\mathrm{d} p / \mathrm{d} t)_{\max }$, and combustion properties (i.e., laminar burning velocity, flame radius) of DME-air mixtures at different initial conditions. The experimental results indicate that the variation between $p_{\max }$ and DME concentration $\left(C_{\mathrm{DME}}\right)$ exhibits a typical inverse "U" shaped behavior, with the peak $p_{\max }$ at slightly larger than the stoichiometric concentration. $p_{\max }$ is also found to decrease as the initial pressure goes down. As the initial pressure decreases from $100 \mathrm{kPa}$ to $40 \mathrm{kPa}$, the lower flammability limit (LFL) is observed to vary slightly, while the upper flammability limit (UFL) is found to have a more significant drop. The relation between $(\mathrm{d} p / \mathrm{d} t)_{\max }$ and $C_{\mathrm{DME}}$ behaves similarly as that of $p_{\max }$ as a function of $C_{\mathrm{DME}}$, and the explosion pressure rises more abruptly at higher initial pressure. A satisfactory agreement is also found between the laminar burning velocity determined experimentally from the pressure measurement and that computed by PREMIX simulations. The present experimental results also show that the increase of the dimensionless radius of the flame is slower at higher initial pressure.

Keywords: Dimethyl ether; Maximum explosion pressure; Flammability limits; Maximum rate of pressure rise; Laminar burning velocity; Flame radius. 


\section{Introduction}

Dimethyl ether $\left(\mathrm{DME}: \mathrm{CH}_{3} \mathrm{OCH}_{3}\right)$ is a promising oxygenated fuel that has the potential to be used as an alternative to natural gas for power production and as a substitute for diesel fuel. DME has high oxygen content of 35 \% by weight, making the combustion smokeless and a high tolerance to exhaust gas recirculation [1]. The use of DME has been proven to significant decrease particulate formation, nitrogen or sulfur oxides $\left(\mathrm{NO}_{\mathrm{x}}\right.$ and $\left.\mathrm{SO}_{\mathrm{x}}\right)$, and carbon monoxide (CO) emission [2, 3]. DME also has a high Cetane number of 55 to 60 and a boiling point of $-25{ }^{\circ} \mathrm{C}$. These properties are ideal for fast mixture formation, reduction in ignition delay, and cold start for diesel engines [4].

Due to its potential as a future alternative fuel, the combustion characteristics of DME have attracted significant attention in recent years [5-10]. A number of experimental and numerical studies can be found in the literature on the combustion and emission characteristics of DME under engine conditions [11-13]. Fundamental properties such as flammability and laminar burning velocities [14-17], and combustion processes of DME under turbulent conditions [3] were also reported. Detailed chemical mechanisms for low and high temperature DME oxidation have been developed and validated [18, 19], and a recent mechanism for DME mixture at high pressures was also constructed by Burke et al. [20]. Furthermore, the effects of DME addition on the high-temperature ignition and burning properties of methane-air mixtures were studied experimentally and numerically [21]. Premixed and non-premixed ignition of methane/DME binary fuel blends with hot air has been investigated through numerical simulation with detailed chemistry and complete thermo-chemical as well as transport properties [22]. Detonation velocities and characteristic cell sizes of DME-oxygen and DME-air mixtures have been measured by $\mathrm{Ng}$ et al. [23] and Diakow et al. [24], and the explosion and detonation 
characteristics of DME were experimentally investigated using a 180-L spherical vessel and a large-scale detonation tube by Mogi and Horiguchi [25]. In addition, experiments were also carried out to examine the leakage and explosion of liquid DME [26].

While DME flames have been studied extensively, comparatively little information exists on the explosion characteristics, e.g., flammability limits, maximum explosion pressure, $p_{\max }$, maximum rate of pressure rise, $(\mathrm{d} p / \mathrm{d} t)_{\max }$ of DME at various initial conditions. The knowledge of the explosion characteristics of DME is of importance to ensure the safety in industries that produce or use it. A realistic assessment of the explosion hazards of DME is necessary for preventive measures of explosion accidents and the design of effective mitigation schemes. Among those aforementioned combustion and explosion characteristics, a key combustion property is the laminar burning velocity $\left(S_{\mathrm{L}}\right)$ which is the velocity of a steady one-dimensional adiabatic free flame propagating in the doubly infinite domain [27]. It received particular attention not only because it represents a basic characteristic property (e.g., reactivity, diffusivity, and exothermicity) of the premixed combustible gasses [28], its accurate knowledge is also essential for engine design, modeling of turbulent combustion, and validation of chemical kinetic mechanisms. In addition, the determination of laminar burning velocity is very important for the analysis and calculations used in the field of explosion protection [29]. Besides experimental measurement, the laminar burning velocity can also be estimated by numerical calculation through PREMIX simulations [30], or by semi-empirical mathematical model [31, 32]. The results obtained from experimental measurement and numerical calculation can then be compared for validation and assessment, together with data reported in the literature [4, 33].

The objective of the present study was twofold. First, the explosion parameters of DME-air mixtures are systematically measured from experiment. The explosion parameters include: the 
maximum explosion pressure $p_{\max }$, both lower flammability limit (LFL) and upper flammability limit (UFL), and the maximum rate of pressure rise $(\mathrm{d} p / \mathrm{d} t)_{\max }$. Second, the combustion characteristics (i.e., laminar burning velocity and the evolution of flame radius) are examined in detail under different initial conditions. The laminar burning velocity obtained from different methods are also compared and discussed.

\section{Experimental details}

\subsection{Experimental setup}

Measurements of the explosion parameters in DME-air mixtures were carried out in a standard 20-L explosion spherical vessel conforming to the international standard ISO6184-1, see Fig. 1. It essentially consists of an explosion chamber, an electric ignition system, a control unit, a data acquisition system, a release valve, a vacuum pump and an air compressor. High-voltage electric spark was used to supply ignition energy as in previous studies [34-39]. The igniter was mounted at the center of the spherical bomb and a spark energy of $10 \mathrm{~J}$, estimated from $1 / 2 C U^{2}$ ("C" and " $U$ " refer the capacitance and voltage, respectively. $C=0.1102 \times 10^{-3} \mathrm{~F}, U=426 \mathrm{~V}$ ), was delivered by an electric ignition system.

\subsection{Experimental procedure and conditions}

For the explosion experiments, gas concentrations were regulated by the gas partial pressures. The purity of the DME used in this experiment is $99.8 \%$. During the experiments, the explosion pressure evolutions were measured by a PCB pressure transducer installed in the vessel wall and recorded by a data acquisition system for each shot. These data yielded values of the maximum explosion pressure and maximum rate of pressure rise as illustrated in Fig. 2. This figure shows 
a typical pressure history of the DME-air of $C_{\mathrm{DME}}=10 \%$ at an initial pressure $p_{0}$ of $100 \mathrm{kPa}$.

The combustion time $t_{\mathrm{c}}$ is defined as the period from ignition to the time when the overpressure reaches its maximum. The measurements were repeated at least 3 times, and results were presented in the figures with error bars determined by the standard deviation. The main sources of the small variation can stem from the effect of wall cooling, ignition source, the degree of mixture homogeneity and asymmetry [40]. In this study, a wide range of initial conditions of DME-air mixtures were used. The initial pressure ranges from $40 \mathrm{kPa}$ to $100 \mathrm{kPa}$, and fuel concentrations are from 3 to19.5 \%.

\section{Results and discussion}

\subsection{Maximum explosion pressure}

Gas explosion max-overpressure is an important parameter of evaluating the explosion hazard. It reflects the energy distribution of explosive waves in their propagation process [41-46]. The measurement of the explosion pressure in quiescent DME-air mixtures with various compositions at the ambient condition are summarized in Table 1. In this table, $p_{\max }$ and its corresponding $t_{\mathrm{c}}$ are directly obtained from the pressure history. For comparison, the adiabatic pressure $p_{\text {ad }}$ is also given and is calculated from thermo-chemical analysis using the GASEQ software [47]. These experimental data of $p_{\max }$ are also compared with those reported by Mogi and Horiguchi [25], and a curve fit of $p_{\max }$ using smoothing splines is also given for better comparison, see Fig. 3. The explosion pressure reaches its maximum value at a composition of $7.5 \%$, which is slightly larger than the stoichiometric concentration (6.5\%). A similar behavior is also observed by Mogi and Horiguchi [25] in their 180-L spherical vessel. Near the stoichiometric condition, both the present data as well as the results by Mogi and Horiguchi [25] agree well with the adiabatic explosion pressure determined from chemical equilibrium within 
the experimental uncertainties. The experimental measurement starts to deviate from the adiabatic pressure at off-stoichiometric conditions, prominently on the rich side. As pointed out by Mogi and Horiguchi [25], at those conditions the combustion speed decreases and the event departs from its constant-volume explosion character. Incomplete combustion and the effect of cooling also give rise to this discrepancy, which are susceptible to the scale of the apparatus. In fact, it can also be seen from Fig. 3 that, the results of $p_{\max }$ from this study are slightly larger than those of Mogi and Horiguchi near stoichiometric concentration, though within experimental uncertainties. A contrary behavior is also observed as the composition tends to both the fuel lean and rich sides. It is noteworthy that in [25], Mogi and Horiguchi used a 180-L spherical vessel, while the present study is performed using a 20-L one. Thus, the discrepancy at off-stoichiometric conditions can be caused by the wall cooling effects. Near stoichiometric conditions, the combustion speed is high and the cooling rate has less influence on the overpressure. However, for incomplete combustion where the temperature is lower (i.e., at off stoichiometric conditions), the combustion speed becomes slower, which allows a longer time scale of the phenomenon for the cooling effect to come into play. The faster cooling of a smaller volume in the 20-L chamber, as compared to the 180-L large-scale apparatus used by Mogi and Horiguchi [25], thus results in a lower overpressure.

Figures 4 to 6 show the results of $p_{\max }$ for different DME compositions at an initial pressure lower than the atmospheric condition, i.e., $80 \mathrm{kPa}, 60 \mathrm{kPa}$ and $40 \mathrm{kPa}$. To show the general trend in the experimental data, curve fits using a third order polynomial are also plotted for better visualization. Note that there is no previous experimental data at those pressure values for direct comparison. Therefore, the measured data are merely compared with the chemical equilibrium results obtained using the GASEQ software [47]. Similarly, large difference is observed as the 
condition moves toward the LFL and UFL. Again, the theoretical maximum explosion pressure determined from the equilibrium calculation is based on the hypothesis of ideal adiabatic explosion. As the composition tends to fuel-lean or fuel-rich sides, not only incomplete reaction occurs but also the heat loss to the surrounding can affect the explosion process, making the measured values different from the chemical equilibrium calculation of an ideal adiabatic explosion. It is observed from Figs. 4 to 6 that the value of $p_{\max }$ goes down as the initial pressure decreases. This observation perhaps suggests that the faster reactivity induced by the higher initial pressure reduces the effect of heat losses on the explosion process. Hence, the higher initial pressure may maintain higher explosion temperature, which in turn results in the rise of overpressure.

\subsection{Flammability limits}

Table 2 shows the LFL and UFL for the DME-air mixture at different initial pressures. These limits were determined when half of the shots at the same condition indicate no occurrence of explosion. It is observed that the LFL has only a small fluctuation as the initial pressure decreases, i.e., only a small increase from $3.5 \%$ to $3.75 \%$ as the initial pressure changes from $100 \mathrm{kPa}$ to $40 \mathrm{kPa}$. However, the UFL is found to have relatively a more significant drop, which changes from $19 \%$ to $12.5 \%$. Reducing the initial pressure is found to narrow the interval width of these two limits. It is worth to point out that this observed behavior is similar to hydrogen/air [48] in which the lower flammability limit is not significantly sensitive to the initial pressure, while the latter has more significant effect on the UFL. From the chemical kinetic point-of-view, the effect of pressure increase has an influence on the reaction rates, especially those involved third body collisions. As shown in [33], reaction steps involving $\mathrm{H}$ and methyl radicals show 
greater sensitivity for rich mixtures at high pressure. Such kinetic effect may thus render the UFL more sensitive to the initiate pressure.

\subsection{Maximum rate of pressure rise}

The maximum rate of pressure rise $(\mathrm{d} p / \mathrm{d} t)_{\max }$ is a commonly examined parameter for explosion characteristics evaluation and used in deflagration index determination as in several previous studies [49, 50]. The results of $(\mathrm{d} p / \mathrm{d} t)_{\max }$ as a function of DME concentration at different initial pressures are shown in Fig. 7. It can be seen that, the relation between $(\mathrm{d} p / \mathrm{d} t)_{\max }$ and $C_{\mathrm{DME}}$ is very similar as that of $p_{\max }$ as a function of $C_{\mathrm{DME}}$. The result indicates that the pressure rises more abruptly at higher initial pressure. While for the same initial pressure, the value of $(\mathrm{dp} / \mathrm{d} t)_{\max }$ is larger near the stoichiometric condition.

It is noteworthy that the rate of pressure rise reaches its maximum value at a slightly higher concentration of approximately $7.5 \%(\varphi=1.159)$ than the stoichiometric condition $(\varphi=1)$, with a mean value of $46.09 \mathrm{MPa} / \mathrm{s}$. Although this behavior is similar to that for the natural gas (NG)-air mixture observed in Zhang et al. [29] (with an average value of $18.86 \mathrm{MPa} / \mathrm{s}$ at the NG concentration of $10.5 \%$ or $\varphi=1.117$ ), yet the pressure increases more abruptly in DME-air than in NG-air mixtures.

\subsection{Laminar burning velocity}

Laminar burning velocity $\left(S_{\mathrm{L}}\right)$ is a unique property of a combustible mixture, indicating its reactivity and exothermicity in a given diffusive medium. Since it contains the physico-chemical information of the mixture, many premixed flame phenomena, e.g., extinction, flash back, blow-off, and turbulent flame propagation, can be characterized with $S_{\mathrm{L}}$ being a reference 
parameter [28]. In this study, the laminar burning velocity is computed through two different methods. The first one uses the PREMIX module of the CHEMKIN-II. The PREMIX code adopts a hybrid time-integration/Newton-iteration technique to solve the steady-state mass, species and energy conservation equations for a freely propagating flame. It has been widely used in many previous studies [21, 51-54]. In this study, 1200 grid points are imposed in the PREMIX calculations to assure a fully converged prediction. Also a small time-step $\Delta t=$ $5.0 \times 10^{-7} \mathrm{sec}$ is used for the computation. The present PREMIX calculation is coupled with the reaction scheme [14] involving 46 species and 263 reactions. This reaction mechanism was also used previously by Chen et al. [21] to perform PREMIX calculations of the laminar burning velocities for $\mathrm{DME} / \mathrm{CH}_{4} / \mathrm{air}$ mixtures. The mechanism was verified by Chen et al. [21] by comparing measured laminar burning velocities from experiment with calculations and the result shows reasonable agreement with the largest difference less than $10 \%$. The second method considers a mathematical model proposed by Dahoe et al. [31, 32], in which the laminar burning velocity depends on $p_{\max }$ and $\mathrm{d} p / \mathrm{d} t . S_{\mathrm{L}}$ calculated by this model was also used in our previous study of NG-air mixtures [29]. The model gives the following expression:

$$
S_{\mathrm{L}}=\frac{1}{\left(p_{\max }-p_{0}\right)} \frac{1}{3}\left(\frac{4 \pi}{3 V}\right)^{-1 / 3}\left(\frac{p_{0}}{p}\right)^{1 / \gamma}\left[1-\left(\frac{p_{0}}{p}\right)^{1 / \gamma} \times\left(\frac{p_{\max }-p}{p_{\max }-p_{0}}\right)\right]^{-2 / 3} \frac{d p}{d t}
$$

where $V$ is the vessel volume, $p$ and $p_{0}$ are the actual pressure and initial pressure, $\gamma$ the adiabatic coefficient of the unburned gas. $S_{\mathrm{L}}$ is determined by a fitting method proposed by Dahoe, in which $S_{\mathrm{L}}$ is calculated by fitting the pressure history measurement (i.e., actual pressure $p$ and $\mathrm{d} p / \mathrm{d} t)$. A pressure $(p)$ - laminar burning velocity $\left(S_{\mathrm{L}}\right)$ curve is then obtained. Afterwards, $S_{\mathrm{L} 0}$ at the reference pressure (i.e., $100 \mathrm{kPa}$ ) can be determined by the extrapolate data from a linear curve fit of $p-S_{\mathrm{L}}$. [55-57]. $S_{\mathrm{L}}$ is calculated at a flame radius greater than $6 \mathrm{~mm}$ to avoid the effect 
associated to the spark ignition [58], so the result can be considered as an ideal spherical flame

241

242

243

244

propagating outward.

The laminar burning velocity of DME-air mixtures at different equivalence ratios under 100 kPa determined using the two aforementioned techniques are shown in Fig. 8. The reported results by Qin and Ju [33] and Daly et al. [4] are also included in the same figure for comparison. As shown in Fig. 8, it appears that the computed laminar burning velocity from Eq. (1) agrees reasonably well with the PREMIX simulation. The largest difference between these two sets of data is $42.93 \%$ at the fuel rich condition at $100 \mathrm{kPa}$. At this condition however, the results from Eq. (1) are very close to the experimental data reported by Qin and Ju [33]. Overall, one can argue that the above comparison shows no significant difference for computing the laminar burning velocity using Eq. (1) and the PREMIX code. Similar comparisons of the computed laminar burning velocity of DME-air mixtures at different equivalence ratios with initial pressures of $80 \mathrm{kPa}, 60 \mathrm{kPa}$ and $40 \mathrm{kPa}$ are also shown in Fig. 9. Again, a reasonable agreement between the two results still holds.

Figures 8 and 9 also indicate a decreasing trend of $S_{\mathrm{L}}$ with the increase of initial pressure, e.g., $S_{\mathrm{L}}$ is found to be $61.52 \mathrm{~cm} / \mathrm{s}$ at $40 \mathrm{kPa}$ which is larger than $48.40 \mathrm{~cm} / \mathrm{s}$ at $100 \mathrm{kPa}$ at the same composition of $C_{\mathrm{DME}}=7.5 \%$. The behavior of decreasing trend of $S_{\mathrm{L}}$ with the increase of initial pressure is caused by the increasing density, $\rho_{\mathrm{u}}$, with increasing pressure. As demonstrated by Law [28], the eigenvalue for flame propagation is $S_{\mathrm{L}}=f^{\%} / \rho_{\mathrm{u}}$, (where $f^{0}$ and $\rho_{\mathrm{u}}$ are the mean laminar burning flux and density, respectively). By increasing pressure, $f^{0}$ increases. It demonstrates that the increase in density with pressure dominates over the retarding effect of $S_{\mathrm{L}}$. 


\subsection{Flame radius}

263 The flame radius, $r_{\mathrm{f}}$, is also calculated through the equation proposed by Dahoe et al. [31, 32] as follows:

$$
\bar{r}=r_{\mathrm{f}} / r_{\mathrm{a}}
$$

where $r_{\mathrm{f}}$ is the flame radius, $r_{\mathrm{a}}$ the radius of the vessel and $\bar{r}$ the dimensionless radius of burned

gas. The typical results for stoichiometric DME-air mixtures at different initial pressures are shown in Fig. 10. It can be seen that the flame radius increases just after the time of $0.02 \mathrm{sec}$, and it increases rapidly until it reaches the wall of the spherical chamber. This process is established as the pressure rise stage. Figure 10 also shows that at the same given time, the dimensionless radius of the flame is relatively greater (i.e., the flame propagates to a longer distance at the same time) at lower initial pressure, which is due to the higher burning velocity.

\section{Concluding remarks}

This paper presents a detailed investigation on the explosion characteristics (i.e., maximum explosion pressure, flammability limits, maximum rate of pressure rise) and combustion properties (i.e., laminar burning velocity, flame radius) of DME-air mixtures. Experiments are performed by systematically measuring the pressure evolutions in a standard 20-L explosion spherical vessel.

The present measurement shows that the variation between $p_{\max }$ and DME concentration $\left(C_{\mathrm{DME}}\right)$ exhibits a typical inverse "U" shaped behavior, and $p_{\max }$ reaches its peak value when its equivalence ratio is slightly larger than 1 . It is found from the present measurement that $p_{\max }$ 
decreases as the initial pressure goes down. The flammability region is found to be from $3.5 \%$ to $19 \%$ of DME by volume at the ambient condition. As the initial pressure decreases from 100 $\mathrm{kPa}$ to $40 \mathrm{kPa}$, the LFL varies slightly and shows little sensitivity to the initial pressure, while the UFL exhibits a more significant drop. The experimental data also show that the explosion pressure rises more abruptly at higher initial pressure. The relation between $(\mathrm{d} p / \mathrm{d} t)_{\max }$ and $C_{\mathrm{DME}}$ is found to be very similar to that of $p_{\max }$ as a function of $C_{\mathrm{DME}}$. Laminar burning velocity was also estimated using both the PREMIX simulation and a mathematical model based on the measured pressure evolution, and a satisfactory agreement is found between those results, especially for $C_{\mathrm{DME}} \leq 9.5 \%$. A decreasing trend of $S_{\mathrm{L}}$ is observed with the increase of initial pressure. This is due to the resulting increase in density with pressure causing the decreasing the observed retarding effect of $S_{\mathrm{L}}$. Finally, the calculated dimensionless radius of the flame from the pressure history is found to be smaller at higher initial pressure.

\section{Acknowledgments}

This work is supported by the National Natural Science Foundation of China (Grant No.: 11402092), Fundamental Research Funds for the Central Universities (Grant No.: 222201314030), and the opening project of State Key Laboratory of Explosion Science and Technology, Beijing Institute of Technology (Grant No.:KFJJ15-03M).

\section{References}

[1] S. H. Park, C. S. Lee. Combustion performance and emission reduction characteristics of automotive DME engine system. Prog. Energ. Combust. 39 (2013): 147-168. DOI:10.1016/j.pecs.2012.10.002

[2] X. C. Lu, D. Han, Z. Huang. Fuel design and management for the control of advanced compression-ignition combustion modes. Prog. Energ. Combust. 37 (2011): 741-783. 
[3] K. N. Gabet, H. Shen, R. A. Patton, F. Fuest, J. A. Sutton. A comparison of turbulent dimethyl ether and methane non-premixed flame structure. Proc. Combust. Inst. 34 (2013): 1447-1454. DOI:10.1016/j.proci.2012.06.183

[4] C. A. Daly, J. M. Simmie, J. Würmel, N. Djebaili, C. Paillard. Burning velocities of dimethyl ether and air. Combust. Flame 125 (2001): 1329-1340. DOI:10.1016/S0010-2180(01)00249-8 [5] T. A. Semelsberger, R. L. Borup, H. L. Greene. Dimethyl ether (DME) as an alternative fuel. J. Power Sources 156 (2006): 497-511. DOI:10.1016/j.jpowsour.2005.05.082 [6] R. Chen, H. Wang, H. Wang. Different oxygen levels of dimethyl ether combustion influence numerical simulation. Procedia Engineering 31 (2012): 934-940. DOI:10.1016/j.proeng.2012.01.1124 [7] S. H. Park, S. H. Yoon, J. Cha, C. S. Lee. Mixing effects of biogas and dimethyl ether (DME) on combustion and emission characteristics of DME fueled high-speed diesel engine. Energy 66 (2014): 413-422.DOI:10.1016/j.energy.2014.02.007

[8] S. H. Yoon, J. P. Cha, C. S. Lee. An investigation of the effects of spray angle and injection strategy on dimethyl ether (DME) combustion and exhaust emission characteristics in a common-rail diesel engine. Fuel Process. Technol. 91 (2010): 1364-1372. DOI:10.1016/j.fuproc.2010.04.017

[9] I. M. Youn, S. H. Park, H. G. Roh, C. S. Lee. Investigation on the fuel spray and emission reduction characteristics for dimethyl ether (DME) fueled multi-cylinder diesel engine with common-rail injection system. Fuel Process. Technol. 92 (2011): 1280-1287. DOI:10.1016/j.fuproc.2011.01.018 gasification - Current status, and research and development needs. Prog. Energ. Combust. 39 (2013): 577-605. DOI:10.1016/j.pecs.2013.06.003

[11] C. Arcoumanis, C. Bae, R. Crookes, E. Kinoshita. The potential of di-methyl ether (DME) as an alternative fuel for compression-ignition engines: A review. Fuel 87 (2008): 1014-1030. DOI:10.1016/j.fuel.2007.06.007

[12] S. Kajitani, Z. Chen, M. Oguma. A study of low-compression-ratio dimethyl ether diesel engines. Int. J. Engine Res. 3 (2002): 1-11. DOI:10.1243/1468087021545496

[13] G. Mittal, M. Chaos, C. Sung, F. L. Dryer. Dimethyl ether auto-ignition in a rapid compression machine: Experiments and chemical kinetic modeling. Fuel Process. Technol. 89 (2008): 1244-1254. DOI:10.1016/j.fuproc.2008.05.021 
[14] Z. W. Zhao, M. Chaos, A. Kazakov, F. L. Dryer. Thermal decomposition reaction and a comprehensive kinetic model of dimethyl ether. Int. J. Chem. Kinet. 40 (2008): 1-18. DOI:10.1002/kin.20285

[15] Z. Zhao, A. Kazakov, F. L. Dryer. Measurements of dimethyl ether/air mixture burning velocities by $\begin{array}{llllll}\text { using } & \text { particle image velocimetry. Combust. Flame } 139 \text { (2004): }\end{array}$ DOI:10.1016/j.combustflame.2004.06.009

[16] E. Kaiser, T. Wallington, M. Hurley, J. Platz, H. Curran, W. Pitz, C. K. Westbrook. Experimental and modeling study of premixed atmospheric-pressure dimethyl ether-air flames. J. Phys. Chem. A 35 (2000): 8194-8206. DOI:10.1021/jp994074c

[17] Z. H. Huang, Q. Wang, J. R. Yu, Y. Zhang, K. Zeng, H. Y. Miao, D. M. Jiang. Measurement of laminar burning velocity of dimethyl ether-air premixed mixtures. Fuel 86 (2007): 2360-2366. DOI:10.1016/j.fuel.2007.01.021

[18] P. Dagaut, J. Boettner, M. Cathonnet. Chemical kinetic study of dimethyl ether oxidation in a jet stirred reactor from 1 to 10 atm: Experiments and kinetic modeling. Proc. Combust. Inst. 26 (1996): 627-632. DOI:10.1016/S0082-0784(96)80269-4

[19] P. Dagaut, C. Daly, J. M. Simmie, M. Cathonnet. The oxidation and ignition of dimethyl ether from low to high temperature (500-1600 K): Experiments and kinetic modeling. Proc. Combust. Inst. 27 (1998): 361-369. DOI:10.1016/S0082-0784(98)80424-4

[20] U. Burke, K. P. Somers, P. O'Toole, C. M. Zinner, N. Marquet, G. Bourque, E. L. Petersen, W. K. Metcalfe, Z. Serinyel, H. J. Curran. An ignition delay and kinetic modeling study of methane, dimethyl ether, and their mixtures at high pressures. Combust. Flame 162(2) (2015): 315-330. DOI:10.1016/j.combustflame.2014.08.014

[21] Z. Chen, X. Qin, Y. Ju, Z. Zhao, M. Chaos, F. L. Dryer. High temperature ignition and combustion enhancement by dimethyl ether addition to methane-air mixtures. Proc. Combust. Inst. 31 (2007): 1215-1222. DOI:10.1016/j.proci.2006.07.177

[22] P. Dai, Z. Chen, S. Y. Chen. Ignition of methane with hydrogen and dimethyl ether addition. Fuel 118 (2014): 1-8. DOI:10.1016/j.fuel.2013.10.048

[23] H. D. Ng, J. Chao, T. Yatsufusa, J. H. S. Lee. Measurement and chemical kinetic prediction of detonation sensitivity and cellular structure characteristics in dimethyl ether-oxygen mixtures. Fuel 88 (2009): 124-131. DOI:10.1016/j.fuel.2008.07.029 
[24] P. Diakow, M. Cross, G. Ciccarelli. Detonation characteristics of dimethyl ether and ethanol-air mixtures. Shock Waves 25 (3) (2015): 231-238. DOI:10.1007/s00193-015-0554-7

[25] T. Mogi, S. Horiguchi. Explosion and detonation characteristics of dimethyl ether. J. Hazard. Mater. 164 (2009): 114-119. DOI:10.1016/j.jhazmat.2008.07.133

[26] T. Mogi, H. Shiina, Y. Wada, R. Dobashi. Investigation of the properties of the accidental release and explosion of liquefied dimethyl ether at a filling station. J. Loss Prevent. Proc. 26 (2013): 32-37. DOI:10.1016/j.jlp.2012.09.002

[27] A. A. Konnov. The temperature and pressure dependences of the laminar burning velocity: experiments and modeling. Proc. $7^{\text {th }}$ European Combustion Meeting, Budapest, Hungary, March 30-April 2, (2015).

[28] C. K. Law (2006). Combustion Physics, Cambridge University Press, New York.

[29] B. Zhang, G. L. Xiu, C. H. Bai. Explosion characteristics of argon/nitrogen diluted natural gas-air mixtures. Fuel 124 (2014): 125-132. DOI:10.1016/j.fuel.2014.01.090

[30] R. J. Kee, J. F. Grcar, M. D. Smooke, J. A. Miller. A Fortran Program for Modeling Steady Laminar One-Dimensional Premixed Flames. Report No. SAND85-8240, 1985

[31] A. E. Dahoe, J. F. Zevenbergen, S. M. Lemkowitz, B. Scarlett. Dust explosions in spherical vessels: the role of flame thickness in the validity of the 'cube-root law'. J. Loss Prevent. Proc. 9 (1996): 33-44. DOI:10.1016/0950-4230(95)00054-2

[32] A. E. Dahoe. Laminar burning velocities of hydrogen-air mixtures from closed vessel gas explosions. J. Loss Prevent. Proc. 18 (2005): 152-166. DOI:10.1016/j.jlp.2005.03.007

[33] X. Qin, Y. Ju. Measurements of burning velocities of dimethyl ether and air premixed flames at elevated pressures. Proc. Combust. Inst. 30 (2005): 233-240. DOI:10.1016/j.proci.2004.08.251

[34] B. Zhang, C. H. Bai. Critical energy of direct detonation initiation in gaseous fuel-oxygen mixtures. Safety Sci. 53 (2013): 153-159. DOI:10.1016/j.ssci.2012.09.013

[35] B. Zhang, C. H. Bai, G. L. Xiu, Q. M. Liu, G. D. Gong. Explosion and flame characteristics of methane/air mixtures in a large-scale vessel. Process Saf. Prog. 33 (2014): 362-368.DOI:10.1002/prs.11670

[36] B. Zhang, V. Kamenskihs, H. D. Ng, J. H. S. Lee. Direct blast initiation of spherical gaseous detonations in highly argon diluted mixtures. Proc. Combust. Inst. 33 (2011): 2265-2271. DOI:10.1016/j.proci.2010.06.165 
[37] B. Zhang, N. Mehrjoo, H. D. Ng, J. H. S. Lee, C. H. Bai. On the dynamic detonation parameters in acetylene-oxygen mixtures with varying amount of argon dilution. Combust. Flame 161 (2014): 1390-1397. DOI:10.1016/j.combustflame.2013.11.016

[38] B. Zhang, H. D. Ng, J. H. S. Lee. The critical tube diameter and critical energy for direct initiation of detonation in $\mathrm{C}_{2} \mathrm{H}_{2} / \mathrm{N}_{2} \mathrm{O} / \mathrm{Ar}$ mixtures. Combust. Flame 159 (2012): 2944-2953. DOI:10.1016/j.combustflame.2012.06.010

[39] B. Zhang, H. D. Ng, R. Mével, J. H. S. Lee. Critical energy for direct initiation of spherical detonations in $\mathrm{H}_{2} / \mathrm{N}_{2} \mathrm{O} / \mathrm{Ar}$ mixtures. Int. J. Hydrogen Energ. 36 (2011): 5707-5716. DOI:10.1016/j.ijhydene.2011.01.175

[40] M. Hattwig, G. Steen (2004). Handbook of Explosion Prevention and Protection, Wiley-VCH, Weinheim.

[41] B. S. Nie, X. Q. He, R. M. Zhang, W. X. Chen, J. F. Zhang. The roles of foam ceramics in suppression of gas explosion overpressure and quenching of flame propagation. J. Hazard. Mater. 192 (2011): 741-747. DOI:10.1016/j.jhazmat.2011.05.083

[42] B. S. Nie, H. Q. He, C. Zhang, X. C. Li, H. L. Li. Temperature measurement of gas explosion flame based on the radiation thermometry. Int. J. Therm. Sci. 78 (2014): 132-44. DOI:10.1016/j.jijthermalsci.2013.12.010

[43] C. Wang, X. Dong, J. Ding, B. Nie. Numerical investigation on the spraying and explosibility characteristics of coal dust. Int. J. Mining Reclamation and Environment 28 (2014): 287-296. DOI:10.1080/17480930.2014.964041

[44] Z. Wang, M. Pan, S. Wang, D. Sun. Effects on external pressures caused by vented explosion of methane-air mixtures in single and connected vessels. Process Saf. Prog. 33 (2014): 385-391. DOI:10.1002/prs.11668

[45] Z. R. Wang, M. Y. Pan, J. C. Jiang. Experimental investigation of gas explosion in single vessel and connected vessels. J. Loss Prevent. Proc. 26 (2013): 1094-1099. DOI:10.1016/j.jlp.2013.04.007

[46] Z. R. Wang, L. Ni, X. Liu, J. C. Jiang, R. Wang. Effects of $\mathrm{N}_{2} / \mathrm{CO}_{2}$ on explosion characteristics of methane and air mixture. J. Loss Prevent. Proc. 31 (2014): 10-15. DOI:10.1016/j.jlp.2014.06.004

[47] GASEQ. A Chemical Equilibrium Program for Windows. Available from: http://www.c.morley.dsl.pipex.com/

[48] M. Kuzetsov J. Grune, T. Jordan. Flammability limits and laminar flame speed of hydrogen-air 
mixtures at sub-atmospheric pressures. Int. J. hydrogen Energy 37 (22) (2012): 17580-17588. DOI:10.1016/j.ijhydene.2012.05.049

[49] Q. Z. Li, B. Q. Lin, H. M. Dai, S. Zhao. Explosion characteristics of $\mathrm{H}_{2} / \mathrm{CH}_{4} /$ air and $\mathrm{CH}_{4} / \mathrm{coal}$ dust/air mixtures. Powder Technol. 229 (2012): 222-228. DOI:10.1016/j.powtec.2012.06.036

[50] Y. D. Jo, D. A. Crowl. Explosion characteristics of hydrogen-air mixtures in a spherical vessel. Process Saf. Prog. 29 (2009): 216-223. DOI:10.1002/prs.10370

[51] A. Di Benedetto, V. Di Sarli, E. Salzano, F. Cammarota, G. Russo. Explosion behavior of $\mathrm{CH}_{4} / \mathrm{O}_{2} / \mathrm{N}_{2} / \mathrm{CO}_{2}$ and $\mathrm{H}_{2} / \mathrm{O}_{2} / \mathrm{N}_{2} / \mathrm{CO}_{2}$ mixtures. Int. J. Hydrogen Energ. 34 (2009): 6970-6978. DOI:10.1016/j.ijhydene.2009.05.120

[52] M. Kuznetsov, R. Redlinger, W. Breitung, J. Grune, A. Friedrich, N. Ichikawa. Laminar burning velocities of hydrogen-oxygen-steam mixtures at elevated temperatures and pressures. Proc. Combust. Inst. 33 (2011): 895-903. DOI:10.1016/j.proci.2010.06.050

[53] S. K. Paidi, A. Bhavaraju, M. Akram, S. Kumar. Effect of $\mathrm{N}_{2} / \mathrm{CO}_{2}$ dilution on laminar burning velocity of $\mathrm{H}_{2}$-air mixtures at high temperatures. Int. J. Hydrogen Energ. 38 (2013): 13812-13821. DOI:10.1016/j.ijhydene.2013.08.024

[54] C. Prathap, A. Ray, M. R. Ravi. Investigation of nitrogen dilution effects on the laminar burning velocity and flame stability of syngas fuel at atmospheric condition. Combust. Flame 155 (2008): 145-160. DOI:10.1016/j.combustflame.2008.04.005

[55] B. Zhang, H. D. Ng. Explosion behavior of methane-dimethyl ether/air mixtures. Fuel 157 (2015): 56-63. DOI:10.1016/j.fuel.2015.04.058

[56] K. Takizawa, A. Takahashi, K. Tokuhashi, S. Kondo, A. Sekiya. Burning velocity measurement of fluorinated compounds by the spherical-vessel method. Combust. Flame 141 (2005): 298-307. DOI:10.1016/j.combustflame.2005.01.009

[57] E. Salzano, F. Cammarota, A. Di Benedetto, V. Di Sarli. Explosion behavior of hydrogen-methane/air mixtures. J. Loss Prevent. Proc. 25(3) (2012): 443-447. DOI:10.1016/j.jlp.2011.11.010

[58] Z. H. Huang, Y. Zhang, K. Zeng, B. Liu, Q. Wang, D. M. Jiang. Measurements of laminar burning velocities for natural gas-hydrogen-air mixtures. Combust. Flame 146 (2006): 302-311. DOI:10.1016/j.combustflame.2006.03.003 


\section{Tables}

461

462 Table. 1 Mixture compositions for the experimental tests, along with maximum explosion

463 pressure $p_{\max }$, corresponding combustion time $t_{\mathrm{c}}$, and adiabatic pressure $p_{\mathrm{ad}}$

464

Table. 2 Flammability limits of DME-air at different initial pressures

465

466 
Table. 1

471

\begin{tabular}{cccccccc}
\hline Test n. & $\begin{array}{c}\mathrm{DME} \\
\% \mathrm{v} / \mathrm{v}\end{array}$ & $\begin{array}{c}\mathrm{O}_{2} \\
\% \mathrm{v} / \mathrm{v}\end{array}$ & $\begin{array}{c}\mathrm{N}_{2} \\
\% \mathrm{v} / \mathrm{v}\end{array}$ & $\begin{array}{c}p_{\text {ad }} \\
\mathrm{MPa}\end{array}$ & $\begin{array}{c}p_{\max } \\
\mathrm{MPa}\end{array}$ & $\begin{array}{c}p_{\text {ad }}-p_{\max } \\
\mathrm{MPa}\end{array}$ & $\begin{array}{c}t_{\mathrm{c}} \\
\mathrm{s}\end{array}$ \\
\hline 1 & 3.0 & 20.37 & 76.63 & 0.6042 & 0.1000 & 0.5042 & - \\
2 & 3.5 & 20.27 & 76.24 & 0.6699 & 0.1446 & 0.5253 & 0.3574 \\
3 & 4.0 & 20.16 & 75.84 & 0.7316 & 0.4687 & 0.2629 & 0.2612 \\
4 & 5.0 & 19.95 & 75.05 & 0.8406 & 0.8844 & -0.0438 & 0.1064 \\
5 & 6.0 & 19.74 & 74.26 & 0.9244 & 1.0011 & -0.0767 & 0.0726 \\
6 & 6.5 & 19.64 & 73.87 & 0.9548 & 1.0578 & -0.1030 & 0.0732 \\
7 & 7.0 & 19.53 & 73.47 & 0.9770 & 1.0767 & -0.0997 & 0.0610 \\
8 & 7.5 & 19.43 & 73.08 & 0.9908 & 1.0781 & -0.0873 & 0.0668 \\
9 & 8.0 & 19.32 & 72.68 & 0.9971 & 1.0447 & -0.0476 & 0.0610 \\
10 & 9.0 & 19.11 & 71.89 & 0.9953 & 0.9953 & 0.0000 & 0.0736 \\
11 & 10.0 & 18.90 & 71.10 & 0.9847 & 0.9157 & 0.0690 & 0.1042 \\
12 & 11.0 & 18.69 & 70.31 & 0.9704 & 0.7448 & 0.2256 & 0.1752 \\
13 & 12.0 & 18.48 & 69.52 & 0.9540 & 0.5341 & 0.4199 & 0.2888 \\
14 & 13.0 & 18.27 & 68.73 & 0.9358 & 0.3364 & 0.5994 & 0.3867 \\
15 & 14.0 & 18.06 & 67.94 & 0.9161 & 0.2532 & 0.6629 & 1.0900 \\
16 & 15.0 & 17.85 & 67.15 & 0.8949 & 0.1810 & 0.7139 & 1.2050 \\
17 & 16.0 & 17.64 & 66.36 & 0.8724 & 0.1286 & 0.7438 & 1.3134 \\
18 & 17.0 & 17.43 & 65.57 & 0.8486 & 0.1218 & 0.7268 & 1.3265 \\
19 & 18.0 & 17.22 & 64.78 & 0.8236 & 0.1195 & 0.7041 & 1.4118 \\
20 & 19.0 & 17.01 & 63.99 & 0.7972 & 0.1192 & 0.6780 & 1.4339 \\
21 & 19.5 & 16.91 & 63.60 & 0.7836 & 0.1000 & 0.6836 & - \\
\hline
\end{tabular}


Table. 2

481

\begin{tabular}{ccc}
\hline$p_{0}(\mathrm{kPa})$ & LFL $(\% \mathrm{v} / \mathrm{v})$ & UFL $(\% \mathrm{v} / \mathrm{v})$ \\
\hline 100 & 3.50 & 19.00 \\
80 & 3.75 & 15.00 \\
60 & 3.33 & 14.17 \\
40 & 3.75 & 12.50 \\
\hline
\end{tabular}

482

483 


\section{Figure captions}

486

487

Fig. 1 The 20-L explosion spherical vessel (1 = DME, 2 = air).

Fig. 2 Determination of the maximum explosion pressure and the combustion time from a typical experimental pressure history.

Fig. $3 p_{\max }$ as a function of DME concentration, compared with Mogi and Horiguchi [25] and adiabatic pressure from equilibrium calculations $\left(p_{0}=100 \mathrm{kPa}\right)$. A curve fit of $p_{\max }$ is also shown in the plot.

Fig. $4 \quad p_{\max }$ as a function of DME concentration, compared with chemical adiabatic pressure from equilibrium calculations at an initial pressure of $p_{0}=80 \mathrm{kPa}$. A curve fit of $p_{\max }$ is also shown in the plot.

Fig. $5 p_{\max }$ as a function of DME concentration, compared with adiabatic pressure from equilibrium calculations at an initial pressure of $p_{0}=60 \mathrm{kPa}$. A curve fit of $p_{\max }$ is also shown in the plot.

Fig. $6 p_{\max }$ as a function of DME concentration, compared with adiabatic pressure from equilibrium calculations at an initial pressure of $p_{0}=40 \mathrm{kPa}$. A curve fit of $p_{\max }$ is also shown in the plot.

Fig. 7 Maximum rate of pressure rise as a function of DME concentration for different initial pressures. Curve fits (shown by the solid lines) are also provided to show the trend in the data.

Fig. 8 Comparison of the laminar burning velocity from chemical simulation and experiment at an initial pressure of $p_{0}=100 \mathrm{kPa}$, Data from Qin and Ju [33] and Daly et al. [4] are also shown for comparison. 
507

508

509

510

511

512

513

Fig. 9 Comparison of the laminar burning velocity calculated by detailed reaction kinetic simulations and determined from explosion properties: (a) $80 \mathrm{kPa}$, (b) $60 \mathrm{kPa}$; and (c) $40 \mathrm{kPa}$.

Fig. 10 Dimensionless radius of burned DME-air mixtures with an equivalent ratio of $\varphi=1$ at different initial pressures. 


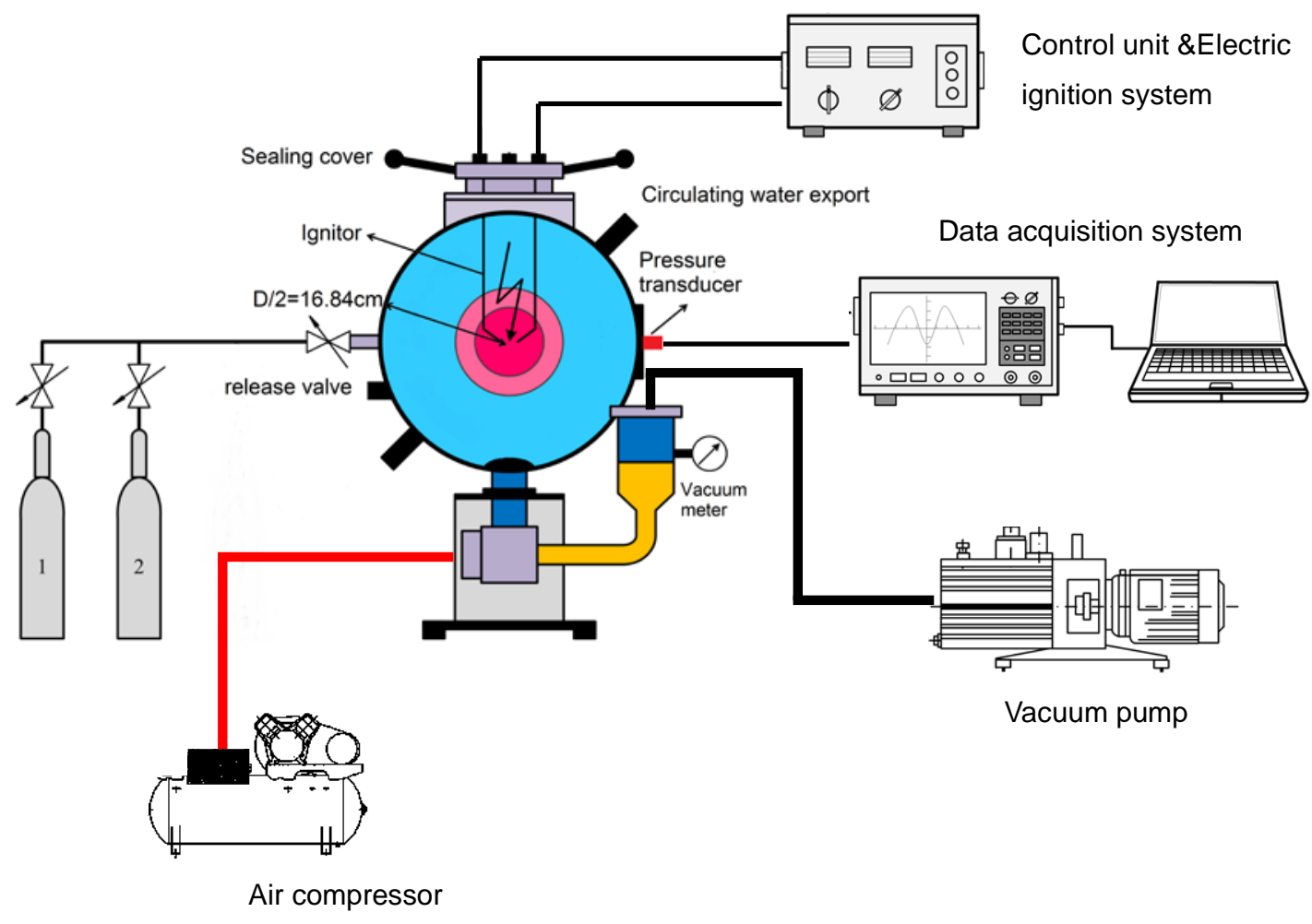

523 


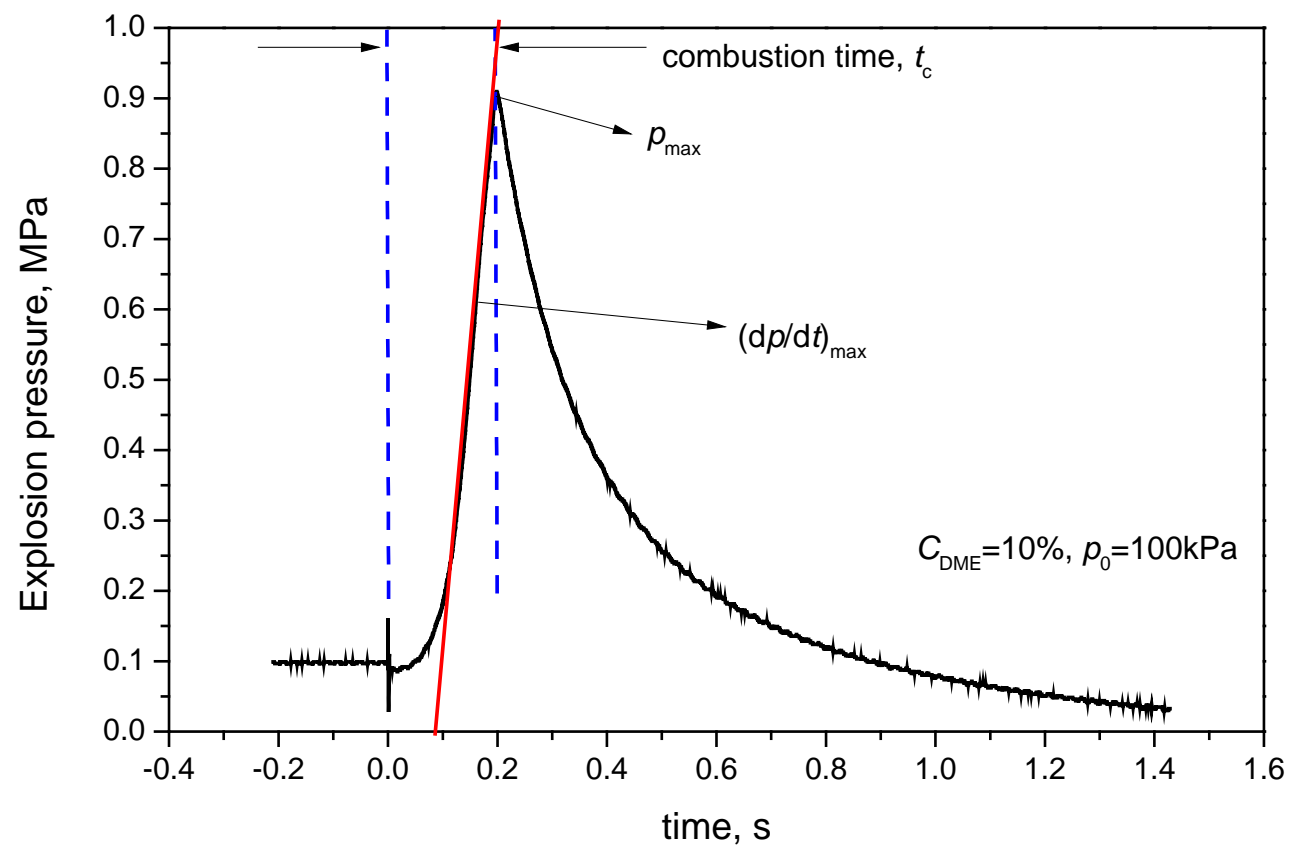

534

Fig.2 


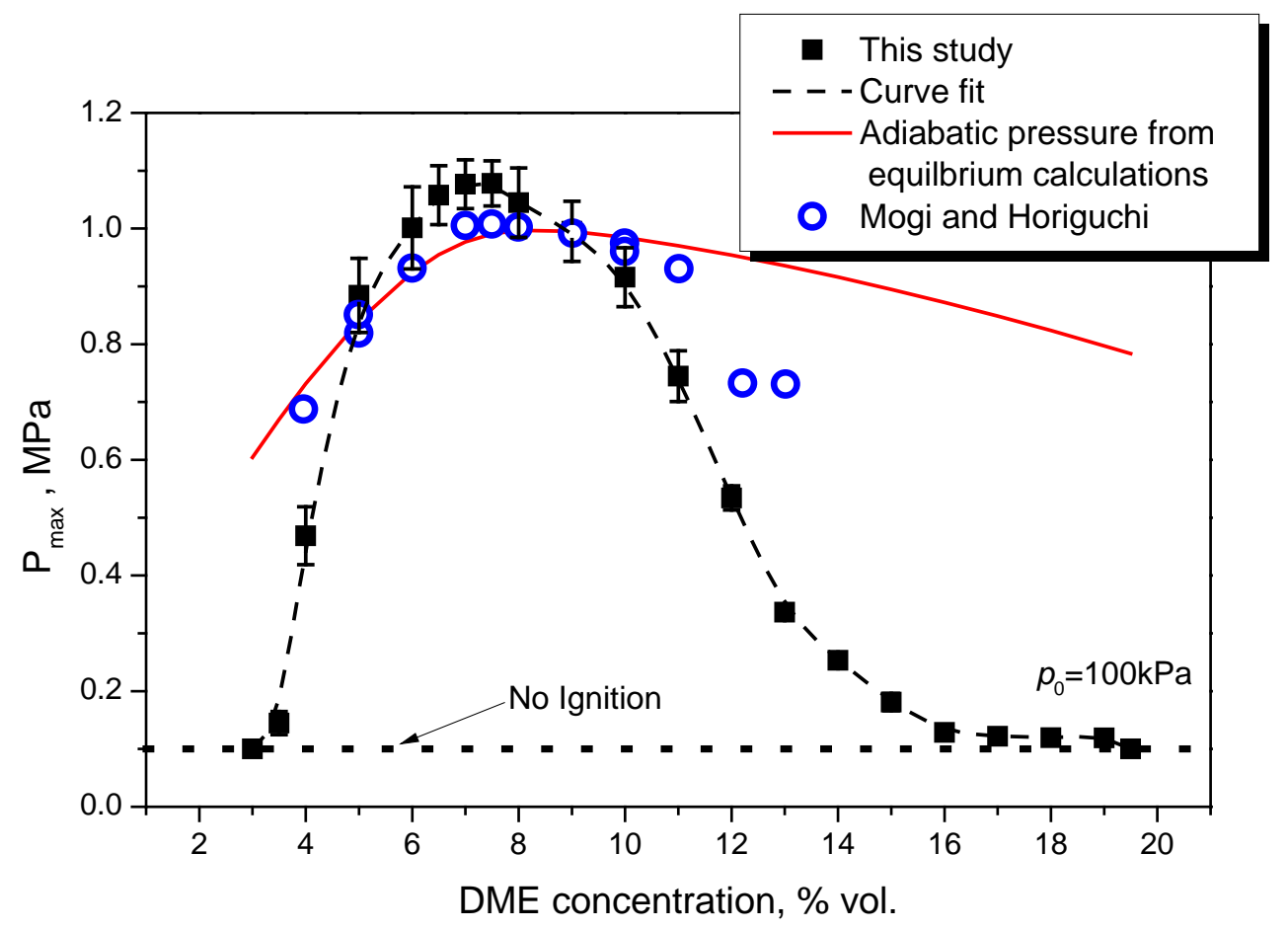




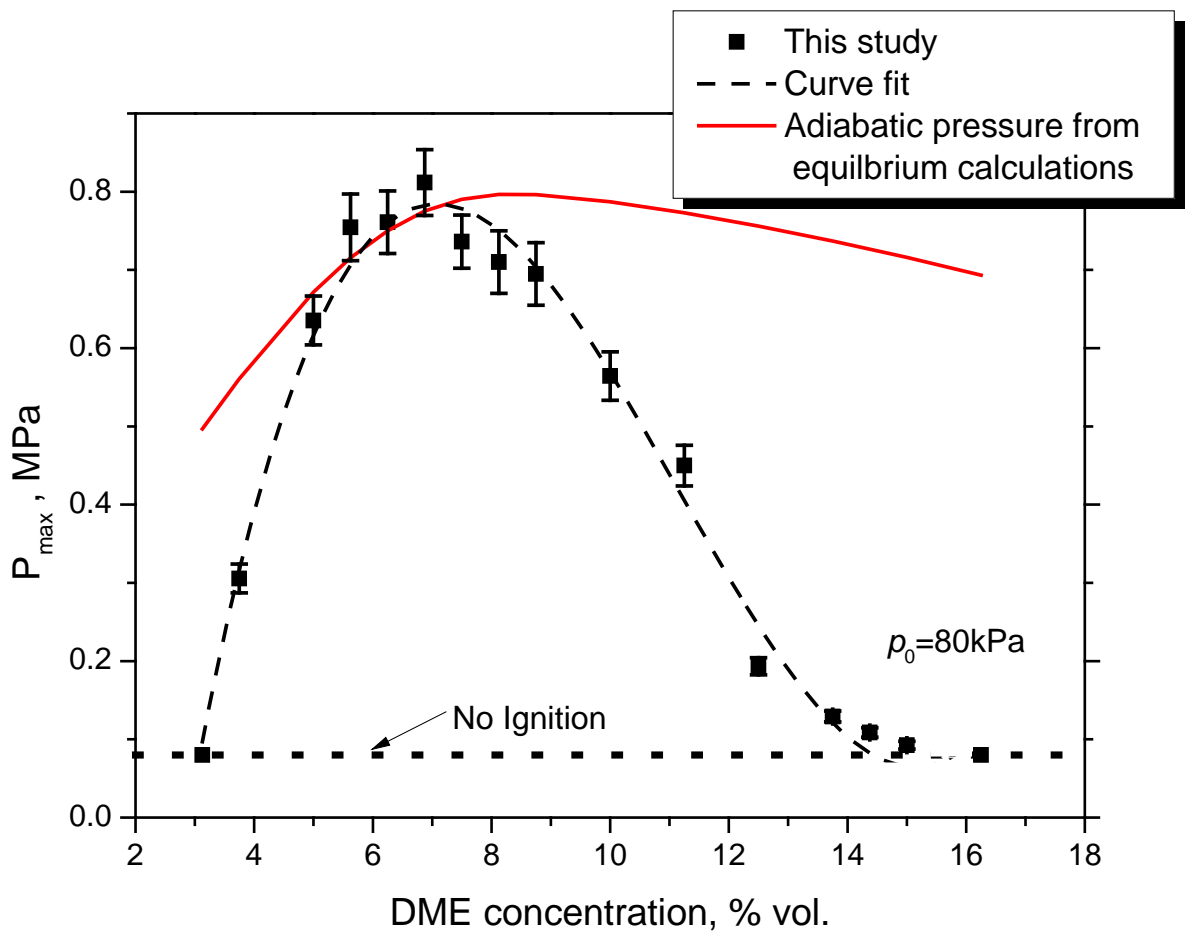




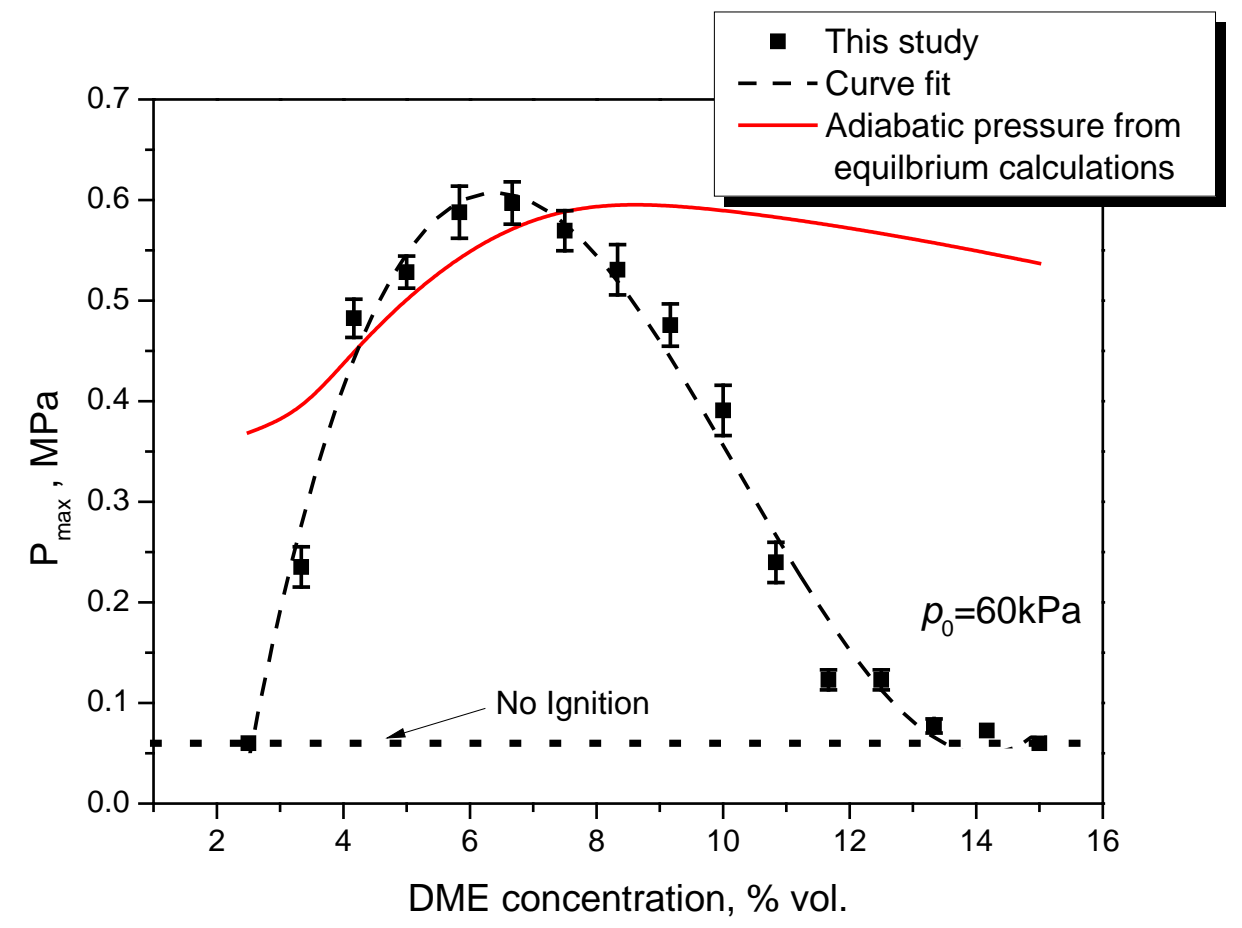




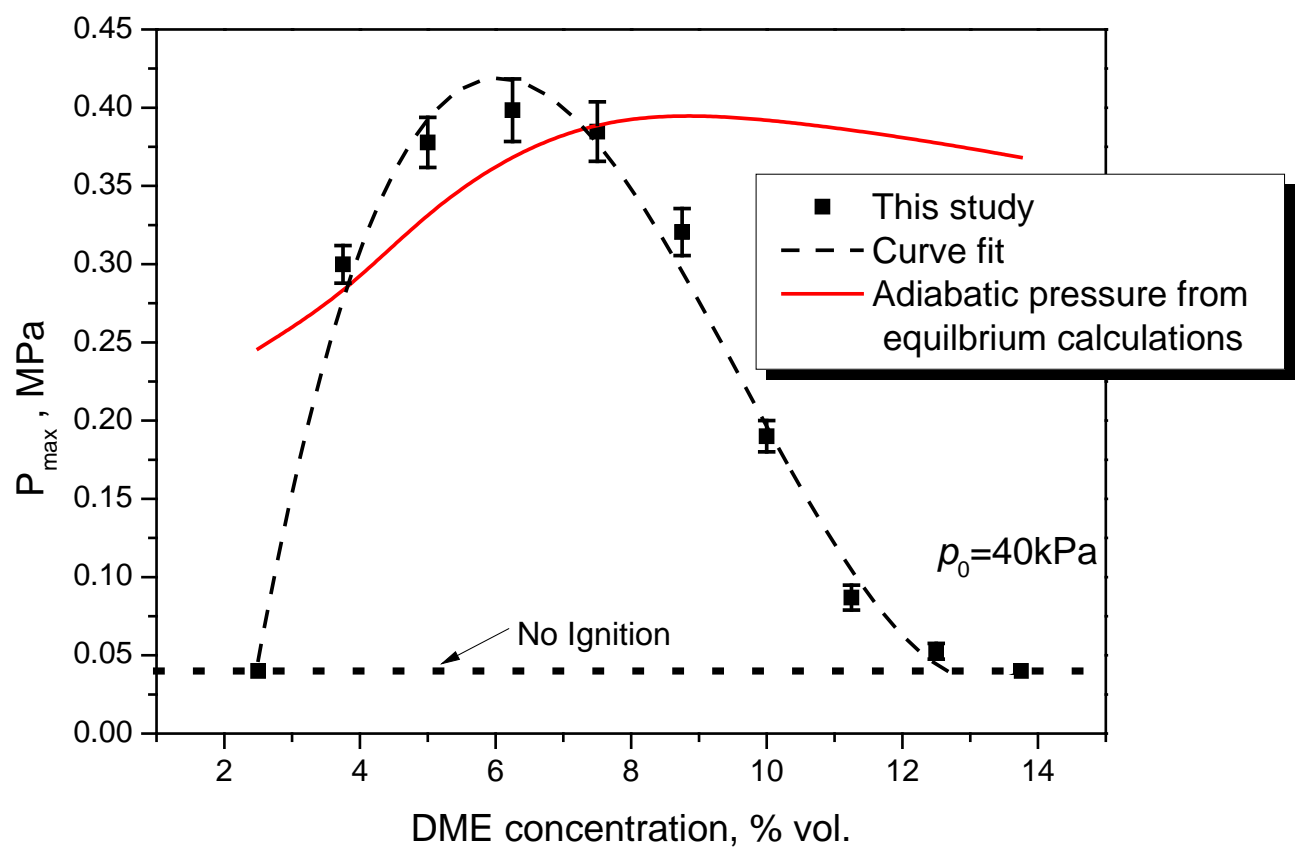




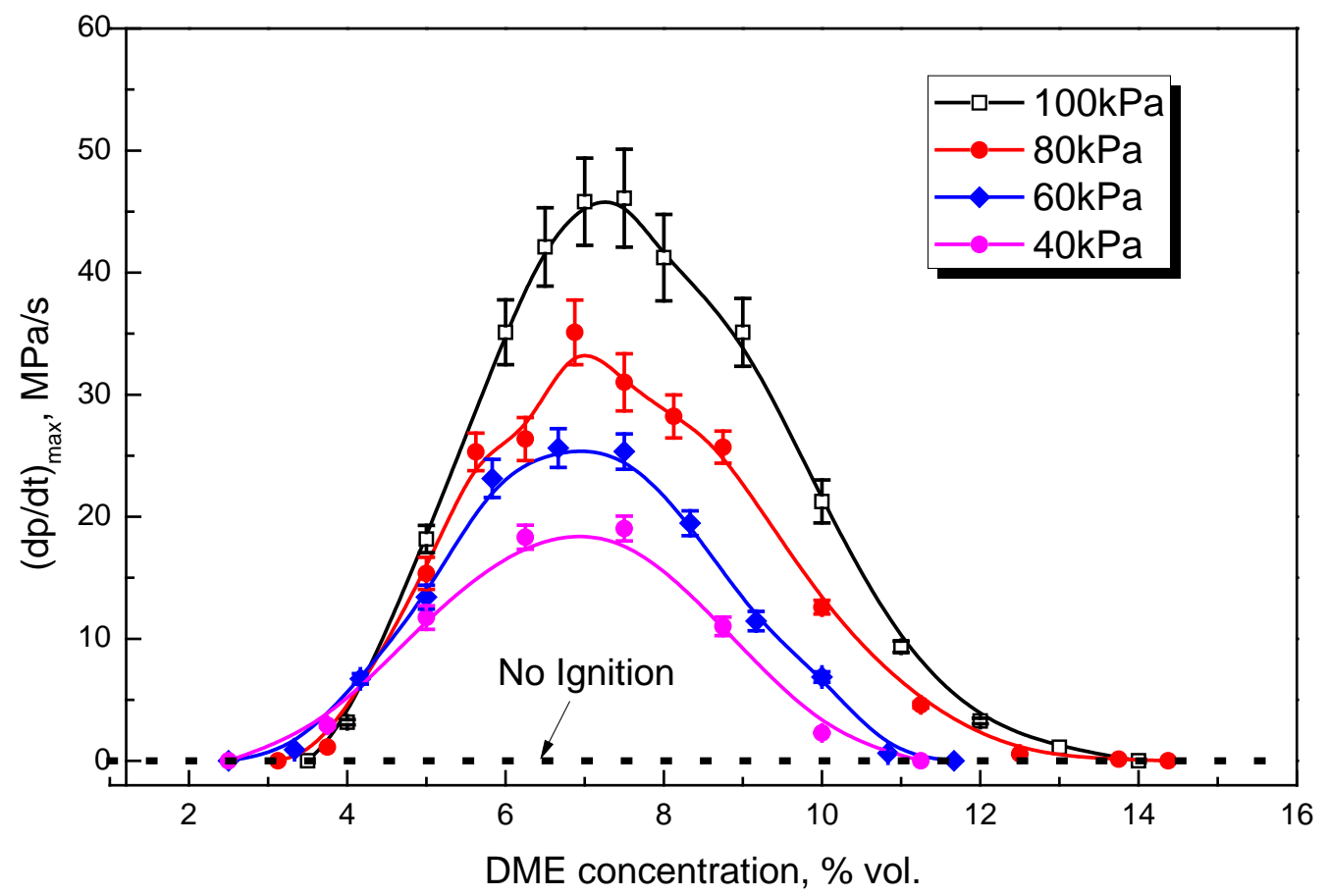




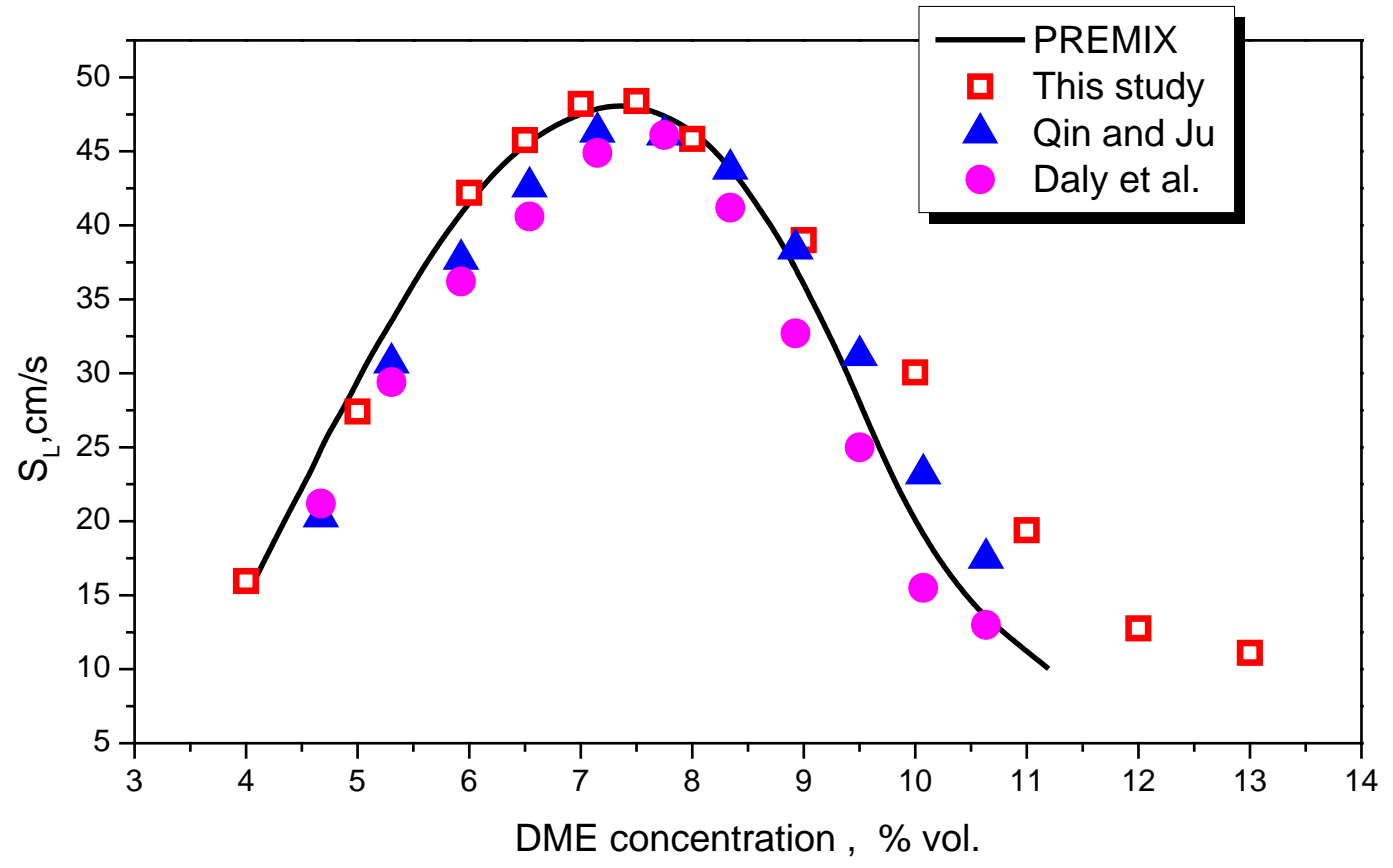

Fig. 8 


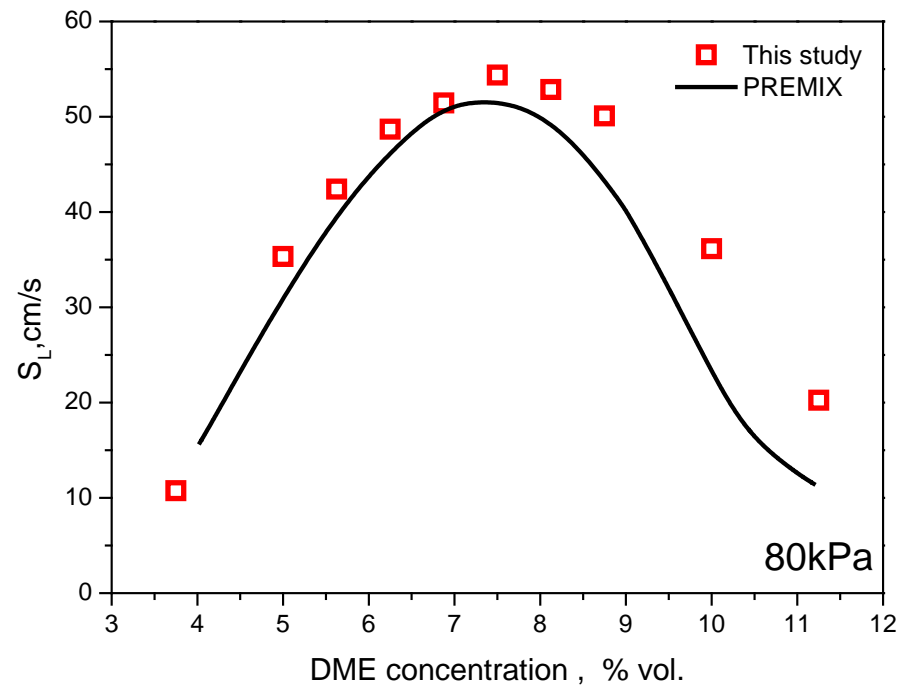

(a)

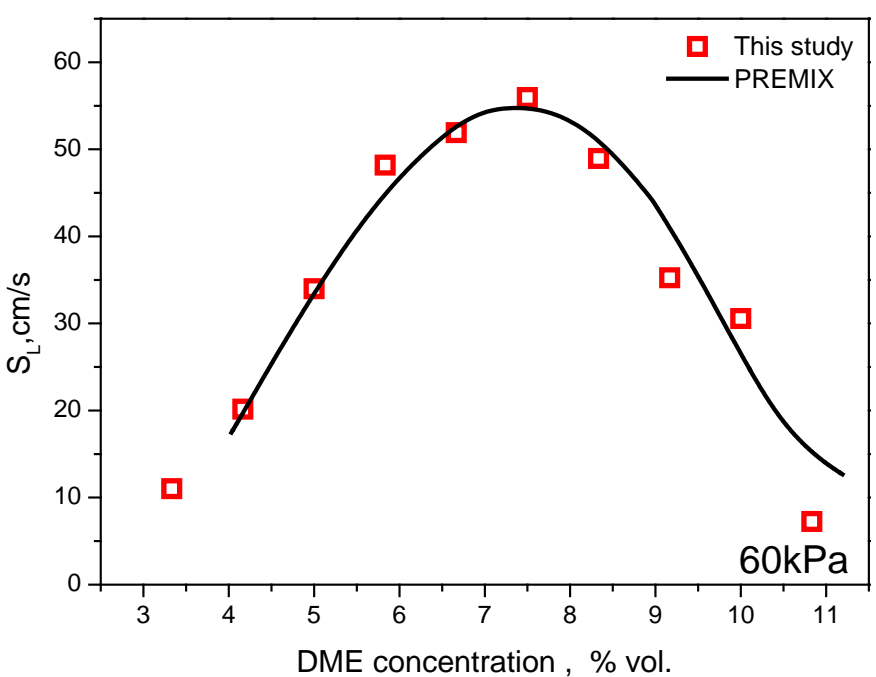

(b)

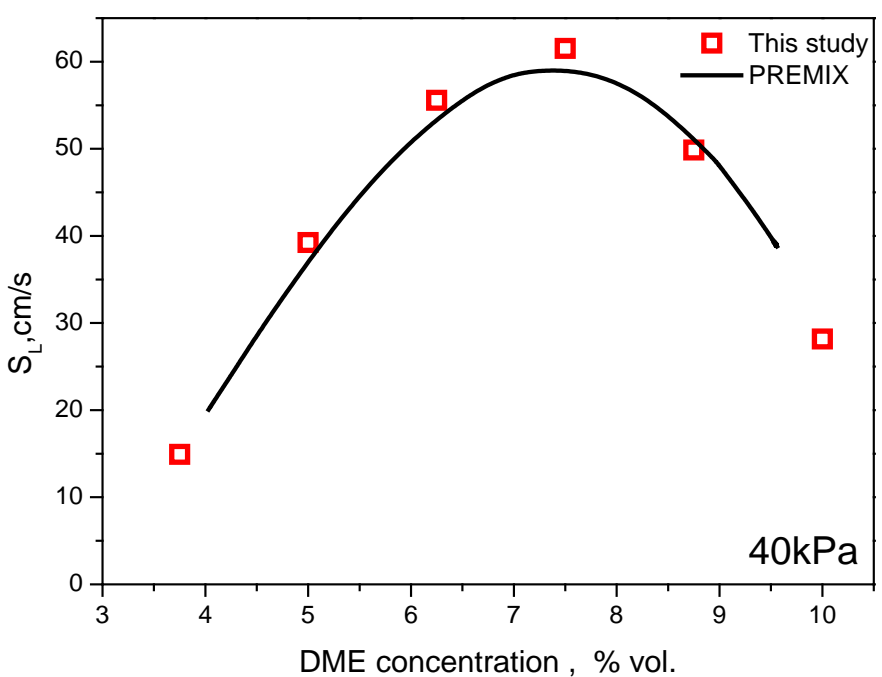

(c)

Fig.9 


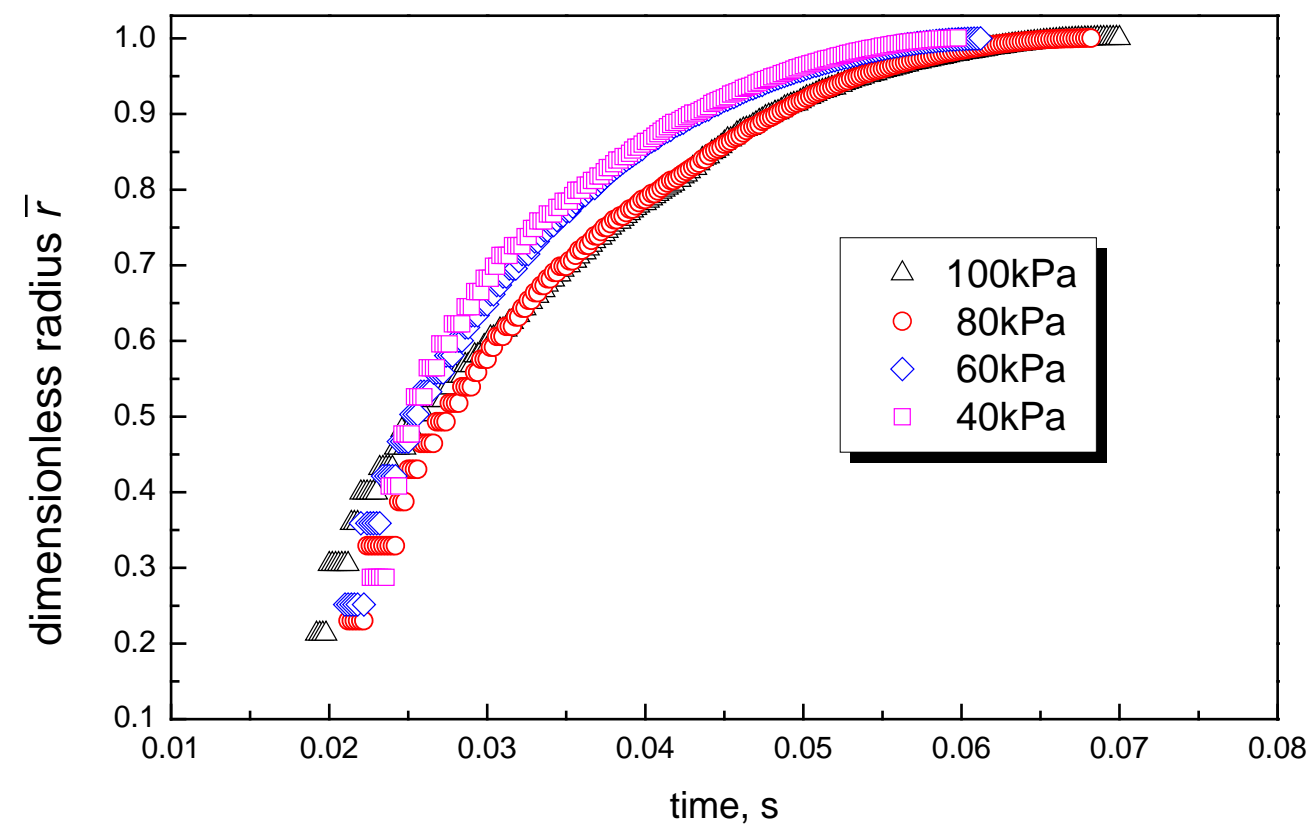

598

599

Fig.10

600 